\title{
Surveillance of surgical site infections to determine incidence, risk factors and microbiologic spectrum following obstetric and gynaecological surgeries
}

\author{
Seetha Panicker*, T. V. Chitra
}

Department of Obstetrics and Gynecology, PSG Institute of Medical Sciences and Research, Coimbatore, Tamil Nadu, India

Received: 18 July 2018

Accepted: 18 August 2018

*Correspondence:

Dr. Seetha Panicker,

E-mail: seethamet@gmail.com

Copyright: (c) the author(s), publisher and licensee Medip Academy. This is an open-access article distributed under the terms of the Creative Commons Attribution Non-Commercial License, which permits unrestricted non-commercial use, distribution, and reproduction in any medium, provided the original work is properly cited.

\section{ABSTRACT}

Background: Surgical site infections (SSI) are one of the major health problems throughout the world with an incidence of 3\%-16\%. Hospital acquired surgical site infection is further complicated by the emergence of multi drug resistant strains. SSI surveillance is an established monitoring tool and has been shown to reduce infection rates. The importance of preventing surgical site infections is well recognized since they lead to increased morbidity, prolonged hospital stay, need for readmission, high end antibiotic treatment and re-surgery. This study was undertaken to determine the incidence, risk factors, and microbiological spectrum of surgical site infections and to identify the multidrug resistant strains. Analysis of the effectiveness of the existing surveillance methods was also done.

Methods: This retrospective study was done for a period of 1-year form Jan 2016 to Dec 2016. All patients with infection following caesarean section and abdominal and vaginal hysterectomy were included. Laparoscopic surgery and patients with preexisting infection were excluded.

Results: Incidence of SSI in present study is $5.27 \%$. The major risk factors identified were obesity, diabetes and prolonged operating time. The commonest infective organism was Klebsiella Pneumoniae in 37\% of which $19 \%$ were ESBL producing and $3.8 \%$ were carbapenemase producing. E. coli was identified in $20 \%$ of isolates. The incidence of ESBL in both isolates was higher.

Conclusions: Regular audit of SSIs is a very effective tool to analyse risk factors, identify causes and plan strategies to prevent infection.

Keywords: Drug resistance, Hospital acquired, Surgical site infection, Surveillance

\section{INTRODUCTION}

Surgical site infections (SSI) are significant source of morbidity, prolonged hospital stay and recovery and rarely mortality. They complicate 3 to $16 \% \cdot{ }^{1-4}$ of all surgeries but even these estimates are likely to be low as some infections occur after the patient's discharge from the hospital or they report to other hospitals with infection. Hospital acquired SSIs are further complicated by the emergence of multidrug resistance strains. The importance of preventing surgical site infections is well recognized since they lead to increased morbidity, prolonged hospital stay, need for readmission, high end antibiotic treatment and resurgery. ${ }^{1,3}$

The Center for Disease Control (CDC) defines SSI as an infection related to an operative procedure that occurs at or near the surgical incision within 30 days. This time frame is extended to 12 months if a surgical implant is used. Infections are further divided into: 
- Superficial involving skin and subcutaneous tissue

- Deep involving deeper soft tissue of the incision like fascia or muscle

- Organ or space involving any part other than the incised body layers.

Surgical wounds are further classified as clean, clean contaminated, contaminated and dirty.

Most obstetric and gynaecological procedures are classified as clean contaminated as the genital tract is entered into controlled fashion and there is no unusual contamination. Some surgeries like pelvis abscess, perforated bowel or positive culture pre-op are classified as dirty. SSI surveillance is an established monitoring tool and has been shown to reduce infection rates.

\section{METHODS}

This retrospective study was conducted in the department of Obstetrics and Gynaecology at a teaching hospital in South India from the period of January 2016 to December 2016.

\section{Inclusion criteria}

- All emergency and elective obstetric and gynaec procedures like caesarean section, abdominal and vaginal hysterectomies and laparotomies were included.

\section{Exclusion criteria}

- Laparoscopic surgeries and patients who had pre-op infection.

The departmental protocol includes two visits after surgery: the first visit a week after discharge and second visit a month later. The charts were analysed at the end of a month after surgery to identify patients with infection. Their case records were analyzed for pre-op risk factors, intra-operative factors like timing of prophylactic antibiotics and duration of surgery and post-operative course. All patients with wound infection had a culture and sensitivity done. The culture report was analysed for the infecting organism and sensitivity pattern. A monthly audit of all SSIs in the department was done to determine the incidence and microbiological spectrum of the infecting organisms. Infection control practices currently in place were also reviewed and analysed to determine if there was a scope for improvement.

\section{RESULTS}

The numbers of surgeries in present study period who fulfilled in present inclusion criteria were 982 caesarean sections and 497 gynaec surgeries. The results are shown in Table 1.

Table 1: Incidence of SSI.

\begin{tabular}{|llll|} 
Type of surgery & $\begin{array}{l}\text { Number of } \\
\text { surgeries } \\
\text { included }\end{array}$ & $\begin{array}{l}\text { Number } \\
\text { of SSI }\end{array}$ & Incidence \\
\hline C section & 982 & 55 & $5.6 \%$ \\
\hline Gynaec surgeries & 497 & 23 & $4.62 \%$ \\
\hline Total & 1479 & 78 & $5.27 \%$ \\
\hline
\end{tabular}

The patients who had wound infection were analysed for pre-operative risk factors like obesity, diabetes, other medical disorders and intra operative factors like prolonged operating time, previous surgeries and presence of malignancy.

As shown in Table 2, obesity was the major risk factor as $48.7 \%$ of patients had BMI of $>25$. Other risk factors included diabetes and prior surgery with adhesions in $19.2 \%$, anemia and hypertension was seen in $12 \%$ of patients. $9 \%$ of patients had prolonged operating time of $>3$ hours.

Table 2: Risk factors of SSI.

\begin{tabular}{|c|c|c|c|c|}
\hline Risk factors & $\begin{array}{l}\text { CS } \\
(55)\end{array}$ & $\begin{array}{l}\text { Gynaec } \\
(23)\end{array}$ & $\begin{array}{l}\text { Total } \\
\text { (78) }\end{array}$ & Percentage \\
\hline $\mathrm{BMI}>25$ & 25 & 13 & 38 & 48.7 \\
\hline Diabetes & 7 & 8 & 15 & 19.2 \\
\hline $\begin{array}{l}\text { Prior surgery } \\
\text { with adhesions }\end{array}$ & 7 & 8 & 15 & 19.2 \\
\hline Anemia & 3 & 7 & 10 & 12.8 \\
\hline Hypertension & 4 & 6 & 10 & 12.18 \\
\hline $\begin{array}{l}\text { Prolonged } \\
\text { operative time } \\
\text { (>3 hours) }\end{array}$ & 1 & 6 & 7 & 9.0 \\
\hline $\begin{array}{l}\text { Bronchial } \\
\text { asthma }\end{array}$ & 3 & 3 & 6 & 7.7 \\
\hline Cardiac disease & 2 & 2 & 4 & 5.1 \\
\hline Malignancy & 0 & 3 & 3 & 3.8 \\
\hline $\begin{array}{l}\text { PROM >12 } \\
\text { hours }\end{array}$ & 2 & NA & 2 & 3.6 \\
\hline $\begin{array}{l}\text { Prophylactic } \\
\text { antibiotics given }\end{array}$ & Give & & & \\
\hline
\end{tabular}

All patients who had discharge from the wound had a culture taken prior to starting antibiotics. The culture report was analysed for infecting organism and sensitivity pattern. The pathogens isolated is shown in Table 3.

Figure 1 shows the month wise analysis of the organisms which were MRSA (Methicillin Resistant Staph Aureus), ESBL (Extended Spectrum Beta Lactamase) and Carbapenemase producers. 
Table 3: Pathogens isolated.

\begin{tabular}{|lllll|}
\hline Pathogens isolates $(\mathbf{N}=107)$ & Caesarean section (55) & Gynaec surgeries (23) & Total (78) & Percentage \\
\hline Klebsiella pneumonia & 20 & 9 & 29 & 37.2 \\
\hline K. pneumonia & 9 & 2 & 11 & \\
\hline K. pneumonia (ESBL) & 10 & 5 & 15 & \\
\hline K. pneumoniae (carbapenamase) & 1 & 2 & 3 & \\
\hline E. coli & 14 & 2 & 16 & 20.5 \\
\hline E. coli & 8 & 1 & 7 & \\
\hline E. coli (ESBL) & 6 & 1 & 13 & 16.7 \\
\hline Staph aureus MSSA & 8 & 5 & 9 & 11.5 \\
\hline Staphylococcus MRCONS & 8 & 1 & 9 & 11.5 \\
\hline Enterococcus faecium & 6 & 3 & 8 & 10.3 \\
\hline Pseudomonas aeruginosa & 5 & 3 & 5 & 6.4 \\
\hline Enterobacter & 4 & 1 & 4 & 5.1 \\
\hline Proteus mirabilis & 3 & 1 & 3 & 3.8 \\
\hline Morganella morganii & 2 & 1 & 3 & 3.8 \\
\hline Strep agalactiae & 3 & 0 & 3 & 3.8 \\
\hline Acinetobacter baumannii & 0 & 3 & 2 & 2.6 \\
\hline Staph aureus MRSA & 1 & 1 & 2 & 2.6 \\
\hline Citrobacter koseri & 2 & 0 & 1 & 1.3 \\
\hline Strep viridans & 1 & 0 & & \\
\hline
\end{tabular}

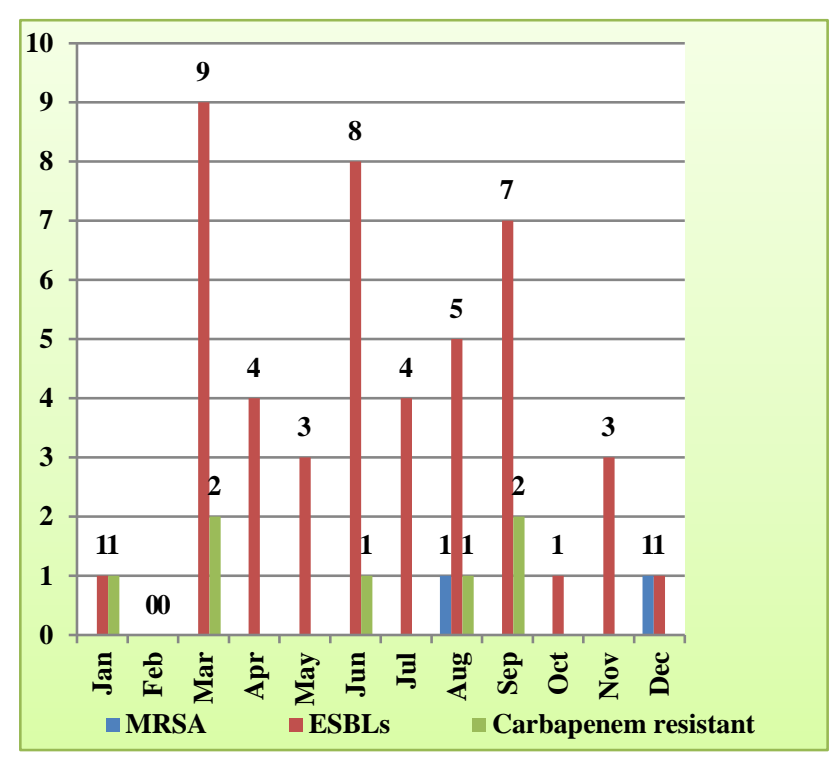

Figure 1: Month wise analysis of drug resistant organisms.

Table 4 shows the cumulative number and percentage of drug resistant organisms. Out of 107 isolates $1.9 \%$ were MRSAs, $43 \%$ were ESBL producers and $6.5 \%$ were Carbapenemase resistant.

Table 4: Analysis of drug resistant organisms.

\begin{tabular}{|lll|}
\hline $\begin{array}{l}\text { Drug resistant } \\
\text { organisms }\end{array}$ & $\begin{array}{l}\text { Number of } \\
\text { isolates }\end{array}$ & $\begin{array}{l}\% \text { out of } \\
107 \text { isolates }\end{array}$ \\
\hline MRSA & 2 & 1.9 \\
\hline ESBLs & 46 & 43 \\
\hline Carbapenemase resistant & 7 & 6.5 \\
\hline
\end{tabular}

\section{DISCUSSION}

According to the WHO, over 1.4 million people worldwide at any one time suffer from hospital acquired infections. In addition to SSIs, these include ventilator associated pneumonia, catheter associated urinary tract infections and blood stream infections.

SSIs are a significant cause of post-operative morbidity, prolonged hospital stay, slow recovery and further surgical intervention like drainage of abscess, debridement and secondary suturing. There is also a perception among patients and their families that SSIs may reflect poor quality of care. ${ }^{5}$ This reduces their satisfaction with the outcome of surgery and delays return to normal work and life. Hospital acquired SSIs vary from hospital to hospital. Continuous audit of SSIs is an important part of infection control practices of a hospital. Identification of the pathogen and their antibiotic sensitivity pattern is crucial to track the emergent of polymicrobial resistant strains.

Routes of entry of infections in operative wounds has long been studied and debated. Both airborne microbes and contact are sources of infection. The major sources include the patient's own flora, hands of the operating personnel and airborne microbes settling on exposed instruments and dressings.

As shown in Table 1 the numbers of surgeries in present study period who fulfilled in present inclusion criteria were 982 caesarean sections and 497 gynaec surgeries. 55 of patients who underwent caesarean section had SSI 
giving an incidence of $5.6 \%$. 23 of patient who underwent gynaec surgeries had SSI giving an incidence of $4.62 \%$. The total incidence was $5.27 \%$.

This compares favorably with the reported rate of $11.8 \%$ in the WHO review of SSIs in low and middle-income countries. $^{5} 93 \%$ of these were superficial infections. Three patients had wound debridement and re-suturing under anaesthesia. One patient had a pelvic collection that got infected. However, it drained spontaneously through the vagina.

SSIs are hospital acquired infections and their occurrence is dependent on many factors. The profile of patients undergoing surgery is also changing. There is increase in the number of patients with multiple co-morbidities and in the older age group. Preoperative factors include patient characteristics like obesity, diabetes, other medical disorders, prior surgery and steroid use. Other pre-operative factors include skin cleaning and hair removal techniques.

Intra operative factors include timing and dose of prophylactic antibiotics, abdominal and vaginal preparation, duration of surgery and technique of wound closure. Post-operative factors include glycemic control in diabetic patients and presence of anemia and blood transfusion.

Table 2 shows the pre-op and intra-op risk factors identified in present study. A systematic review of 57 studies by the WHO from both high income and low and middle income countries identified high body mass index (BMI), diabetes and prolongation of duration of surgery as risk factors associated with increased risk of SSIs .In patients with high BMI, various factors like increase in adipose tissue, need for larger incision, decreased circulation in fat tissue and increase in local tissue trauma related to retraction contribute to the increased SSIs in these patients. Obese patients also have an altered hemostatic balance and decreased immune function.

Hyperglycemia in patients with diabetes is a well-known risk factor for infections including SSIs. A study by AlNiaimi et al compared 2 groups of post-operative patients after gynaecological oncology surgery. Patients whose blood sugar > 150mg/dl were managed either with intermittent subcutaneous insulin injection or insulin infusion. Patients who were on insulin infusion had significantly lower infection rates (19\% versus $29 \%$ $\mathrm{P}=.001){ }^{6}$ Hyperglycemia can have several deleterious effects on host immune functions, stimulation of inflammatory markers, increased thrombotic activity and endothelial cell dysfunction. This is of importance even in non-diabetics as stress hyperglycemia can have the same effects.

Prolonged duration of surgery was associated with increased incidence of SSIs in the majority of studies. There was also a linear correlation between operative time and the likelihood of SSIs. The reasons postulated for this are:

1. With increased operative time the patient's open incision is exposed to the environment for a longer time.

2. Tissue desiccation is more.

3. Tissue concentration of antibiotics will decrease as the procedure continues.

However, it is important to remember prolonged surgery may also mean more complex procedures and other intra operative factors like adhesions which by themselves can increase the likelihood of infection.

Other risk factors included anemia which diminishes the resistance to infection in $12.8 \%$ prolonged PROM $>24$ hours in $3.6 \%$ of caesarean sections and malignancy in $3.8 \%$.

Other risk factors considered important in SSI in a study by Devjani et al included pre-operative hospital stay with exposure to procedures, therapies and hospital micro flora and administration of blood products. Allogenic blood products have immunomodulatory effects that may increase the risk of post-op infections. ${ }^{7}$

The prophylactic antibiotic policy at present in the hospital is administration of Injection Cephazolin $1 \mathrm{gm}$ given within one hour of skin incision and the second dose 6 hours later. All the patients received the prophylaxis however the time was $>1$ hour in few patients. David Classen et al reported that administration of antibiotics within a 2-hour period before an operation was associated with the lowest infection rate. ${ }^{8}$

On analyzing the culture report, Table 3 shows the organisms isolated in present patients. Klebsiella pneumonia was seen in 29 patients $(37.2 \%)$ of these $51 \%$ were ESBL producers and $10 \%$ were carbapenamase producers. The second commonest organism was E coli in 16 patients $(20.5 \%)$ of these $43 \%$ were ESBL producing. Pseudomonas was isolated in $10 \%$. Routine anaerobic cultures were not performed. More than one organism was isolated in 31 out of 78 patients $(39.7 \%)$.

In a study conducted by Devjani De et al the most frequently isolated organism was Acinetobacter species in $32 \%$ followed by Staphylococcus aureus in $22.3 \% .^{9}$ In mild infections, patients were started on Levofloxacin and Metrogyl pending the culture report. In more severe infections Cefotaxime and Metrogyl or Piperacillin/ Tazobactam was started.

The resistance pattern of the infecting organism was also analysed. Figure 1 and Table 4 shows the number and percentage of drug resistant organisms. MRSA infections are of concern and there is need to screen both the patients and the health care workers involved for asymptomatic nasal carriers. In 51 out of 78 patients 
(65\%) infection occurred after discharge from the hospital. This may be due to the policy of early discharge from the hospital. So, post discharge surveillance is important to arrive at a correct estimate of the magnitude of the problem. A WHO review on Global guidelines for SSI prevention reported that $13 \%$ to $71 \%$ of infections occurred after discharge from the hospital. Rosenthal et al determined that $63.8 \%$ of SSIs were detected in hospital and $36.2 \%$ after discharge. ${ }^{10}$

Surveillance of SSIs also includes a review and analysis of the preventive strategies in place in the hospital. Prevention of SSIs requires a multifaceted approach including proper air conditioning and ventilation engineering, appropriate cleaning and disinfection of the operating theatres and proper sterilization of instruments. Proper safeguards for checking sterilization of instruments, maintenance of OR discipline and sustained education of all OR personnel regarding safe practices are no less important. ${ }^{11}$ Hence every hospital should have protocols for prevention of SSIs and follow continuous surveillance of infections.

As part of this, the hospital infection control committee met on monthly basis. The rates of various hospital acquired infections were discussed in the monthly hospital infection control committee meetings. SSI surveillance by surgical staff can also be cross checked by the infection control team. ${ }^{10}$ In addition to the SSI rates in various surgical specialties, ventilator associated pneumonia and catheter associated urinary tract infection and blood stream infection rates were also discussed. Environmental surveillance included air sampling done by settle plate in all OTs and the results were analyzed. The incidence of multi drug resistant organisms in all areas in the hospital was analysed and compared to the previous months. To audit the usage of antibiotics, patients on high end antibiotics was analysed department wise and feedback was disseminated to the concerned department. Hand hygiene compliance by health care workers was also analysed in all acute care areas and feedback disseminated.

The information on Hospital Acquired Infection in developing countries is limited because of the lack of national surveillance systems. ${ }^{12}$ Most of the reported studies are from single hospital and therefore are not representative of the entire country. Prevention of hospital acquired infection is one of the key agendas of various international bodies like the WHO, CDC and others.

Both the WHO and Center for Disease Control and Prevention guidelines for prevention of surgical site infection (2017) included the following strong recommendations ${ }^{5,13}$ :

- Patients are advised to bathe with soap or antiseptic agents at least the night before surgery.
- Skin preparation: Hair removal if required is done only by clipping Shaving is strongly discouraged at all times Intra op skin preparation with alcohol-based chlorhexidine gluconate is recommended.

- Prophylactic antibiotics should be administered 1 hour before skin incision so that serum and tissue concentration are established before the incision is made. For clean and clean contaminated procedures additional prophylactic antimicrobial agents should not be administered after the surgical incision is closed in the operating room even in a presence of a drain. Topical antimicrobial agents should not be applied on the surgical incision.

- Protocols for perioperative glycemic control to be implemented using blood glucose target level of $<200 \mathrm{mg} / \mathrm{dl}$ in patients with or without diabetes.

- Perioperative normothermia should be maintained in all patients. Increased fraction of inspired oxygen should be administered during surgery and after extubation in the immediate postoperative period for patients with normal pulmonary function undergoing general anesthesia.

Transfusion of blood products should not be withheld from surgical patients as a means to prevent SSIs.

\section{CONCLUSION}

Prevention of SSI is an important part of providing optimum care for patients. Throughout the world there is a growing concern about patient safety. This prompted the WHO to launch the World Alliance for patient safety. Prevention of health care acquired infection is the one of the first targets of the Alliance. "Clean care is safer care" was launched in October 2005. A key objective of the programme is to launch a feasible practical approach to improve hand hygiene in healthcare globally. Continuous audit and implementation of infection prevention strategies should part of the standard protocols of every hospital. It is challenging and requires dedication of both time and resources. This includes simple things like hand hygiene, pre-operative bathing and skin preparation that are no less important than tracking of multi drug resistant organisms and usage of high end antibiotics.

\section{ACKNOWLEDGMENTS}

Authors acknowledge the services of Infection Control team and the department of Microbiology.

Funding: No funding sources

Conflict of interest: None declared

Ethical approval: The study was approved by the Institutional Ethics Committee

\section{REFERENCES}

1. Giacometti A, Cirioni O, Schimizzi AM, Del Prete MS, Barchiesi F, D'errico MM, et al. Epidemiology 
and microbiology of surgical wound infections. J Clinical Microbiol. 2000;38(2):918-22.

2. Mulu W, Kibru G, Beyene G, Damtie M. Postoperative nosocomial infections and antimicrobial resistance pattern of bacteria isolates among patients admitted at Felege Hiwot Referral Hospital, Bahirdar, Ethiopia. Ethiopian J Health Sci. 2012;22(1):7-18.

3. Owens CD1, Stoessel K. Surgical site infections: epidemiology, microbiology and prevention. J Hosp Infect. 2008;70 Suppl2:3-10.

4. Saeed KB, Greene RA, Corcoran P, O'Neill SM. Incidence of surgical site infection following caesarean section: a systematic review and metaanalysis protocol. BMJ Open. 2017;7(1):e013037.

5. WHO-Global Guidelines for the Prevention of Surgical Site Infection. World Health Organization. ISBN $97892 \quad 4 \quad 154988$ 2. Available at: http://www.who.int/infectionprevention/publications/ssi-prevention-guidelines/en/

6. Steiner HL, Strand EA. Surgical-site infection in gynecologic surgery: pathophysiology and prevention. Am J Obstet Gynecol. 2017;217(2):1218.

7. De D, Saxena S, Mehta G, Yadav R, Dutta R. Risk factor analysis and microbial etiology of surgical site infections following lower segment caesarean section. Int J Antibiot. 2013;2013.

8. Classen DC, Evans RS, Pestotnik SL, Horn SD, Menlove RL, Burke JP. The timing of prophylactic administration of antibiotics and the risk of surgicalwound infection. New England $\mathbf{J}$ Med. 1992;326(5):281-6.
9. De D, Saxena S, Mehta G, Yadav R, Dutta R. Risk factor analysis and microbial etiology of surgical site infections following lower segment caesarean section. Int J Antibiotics. 2013;2013.

10. Rosenthal R, Weber WP, Marti WR, Misteli H, Reck $\mathrm{S}$, Dangel $\mathrm{M}$, et al. Surveillance of surgical site infections by surgeons: biased underreporting or useful epidemiological data?. J Hospital Infect. 2010;75(3):178-82.

11. Woodhead K, Taylor EW, Bannister G, Chesworth T, Hoffman P, Humphreys H. Behaviours and rituals in the operating theatre: a report from the Hospital Infection Society Working Party on Infection Control in Operating Theatres. J Hospital Infect. 2002;51(4):241-55.

12. Allegranzi B, Nejad SB, Combescure C, Graafmans W, Attar H, Donaldson L, et al. Burden of endemic health-care-associated infection in developing countries: systematic review and meta-analysis. Lancet. 2011;377(9761):228-41.

13. Berríos-Torres SI, Umscheid CA, Bratzler DW, Leas B, Stone EC, Kelz RR, et al. Centers for disease control and prevention guideline for the prevention of surgical site infection, 2017. JAMA Surg. 2017;152(8):784-91.

Cite this article as: Panicker S, Chitra TV. Surveillance of surgical site infections to determine incidence, risk factors and microbiologic spectrum following obstetric and gynaecological surgeries. Int J Reprod Contracept Obstet Gynecol 2018;7:402934. 